\title{
Investigation of Factors Affecting Microdialysis Probe Delivery and Recovery of Puerarin In Vitro
}

\author{
Pengyue Li, Yang Lu, Shouying Du, Huimin Liu and Dan Yan \\ Department of TCM Pharmaceutics, School of Chinese Pharmacy, Beijing University of Chinese Medicine, Beijing 100102, \\ China.
}

*For correspondence: Email: dushouying@263.net

Received: 11 June $2013 \quad$ Revised accepted: 22 October 2013

\begin{abstract}
Purpose: To investigate in vitro the factors affecting microdialysis probe delivery and recovery of puerarin .

Methods: The recovery and delivery of puerarin were tested for extraction efficiency and retro-dialysis methods. Factors such as drug concentration, stirring speed, additives and length of membrane were studied to determine differences between recovery and delivery.

Results: It was observed that the delivery of the targeting analyte was different from its recovery. Both delivery and recovery of puerarin were independent of the concentration of the drug. Probe delivery increased from 62.18 to $67.98 \%$ ( $p<0.01$ ), recovery from 59.19 to $78.44 \%(p<0.01)$, and stirring speed increased from 0 to $800 \mathrm{rpm}$. The difference between them directly correlated with stirring speed in the range 2.99 to $10.46 \%$. Besides, additives, length of membrane also had a strong influence on delivery and recovery. Probe delivery in saline containing $10 \%$ each of ethanol and propylene glycol declined from 62.18 to $42.12 \%(p<0.01)$, while recovery increased insignificantlly $(p<0.01)$. Both delivery and recovery declined while the length of membrane was cut down.

Conclusion: The in vitro experiments indicate that it was not correct to equate delivery with recovery of puerarin in in vivo microdialysis experiments.
\end{abstract}

Keywords: Microdialysis, Puerarin, Recovery, Probe delivery.

Tropical Journal of Pharmaceutical Research is indexed by Science Citation Index (SciSearch), Scopus, International Pharmaceutical Abstract, Chemical Abstracts, Embase, Index Copernicus, EBSCO, African Index Medicus, JournalSeek, Journal Citation Reports/Science Edition, Directory of Open Access Journals (DOAJ), African Journal Online, Bioline International, Open-J-Gate and Pharmacy Abstracts

\section{INTRODUCTION}

Microdialysis is a dynamic technique for sampling. It has been widely applied in many fields in the last half-century and the technique is increasingly getting more sophisticated. It is a method that has been used for sampling freeform drug from the blood and extracellular fluid of different tissues, like muscles, organs, either in animals, human or plants [1]. Owing to the selective permeability of semi-permeable membranes, there were no bio-macromolecules in the collected samples. It is characterized by its continuity, real-time when sampling in vivo and its easy sample pretreatment.

In microdialysis experiments, targeting compounds are removed from the solution surrounding the probe by a diffusion gradient established via the continuous perfusion of blank medium through the probe. Under this nonequilibrium condition, the concentration in the dialysate will always represent a fraction of the real concentration outside. The ratio between the fraction and the actual concentration outside is known as recovery. On the contrary, with the perfusion of drug-containing solution through the 
probe, the ratio between fraction diffused to outside and the perfusion concentration is called as delivery.

Usually, the real concentration of analyte in extracellular fluid (ECF) in vivo experiments can be calculated by dividing the sample concentration by delivery itself or the internal standard added in the perfusion solution [2-5]. However, it is only if there were no significant differences between delivery and recovery in vitro, can the delivery in vivo be considered as the recovery of free-form drug in ECF. However, microdialysis is a sensitive method. The delivery and recovery can be affected by several factors [6].

Puerarin is extracted from Pueraria lobata, a traditional Chinese medicine. Different preparations of puerarin are now being used in clinics in China. Unlike compounds with hydrophilicity or lipophilicity, it is an isoflavone Cglycoside with weak hydrophilicity but poor water solubility. The aim of this study was to investigate the possibility of replacing recovery with delivery in vivo using two methods, namely, extraction efficiency and retro-dialysis methods.

\section{EXPERIMENTAL}

\section{Chemicals}

Puerarin was obtained from National institutes for Food and Drug Control (Beijing, China), sodium chloride from Beijing Chemical Reagents Company (Beijing, China), Methanol $\left(\mathrm{CH}_{3} \mathrm{OH}\right)$ and acetic acid $\left(\mathrm{CH}_{3} \mathrm{COOH}\right)$ from Mreda technology Inc (USA), High purity water was obtained from Hangzhou Wahaha Group Co, Ltd (Zhejiang, China).

\section{Chromatographic conditions}

The high performance liquid chromatography (HPLC) system used consisted of an Agilent LC20AD solvent delivery module, a 10AV UV detector module (Agilent). Sample injections were made into a G2171BA valve with a $100 \mu \mathrm{l}$ injection loop. An injection volume of $20 \mu$ l was used for all sample analyses. The system was operated using Agilen Chem Station B.04.03 software. A Agilent ZORBAX Eclipse Plus $\mathrm{C}_{18}$

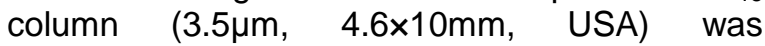
employed. The mobile phase consisted of methanol/1\% CH3COOH (24/76, v/v). All HPLC mobile phases were filtered through a $50 \mathrm{~mm}$, $0.22 \mu \mathrm{m}$ nylon filter (Jinteng Experiment Equipment Co, Ltd) prior to use. An isocratic elution was employed at a flow rate of $1 \mathrm{ml} / \mathrm{min}$. All sample analyses were carried out using UV detection at $250 \mathrm{~nm}$ with a deuterium lamp. The analytical method was developed to be linear in the range $0.08248-8.248 \mu \mathrm{g} / \mathrm{ml}\left(r^{2}=0.9999\right)$. The regression curve was $A=97.1940 C+$ 0.5759 .

\section{Microdialysis system}

Microdialysis probe with membrane length of $10 \mathrm{~mm}$ and $2 \mathrm{~mm}$, molecular weight cut-off of 20 $\mathrm{kDa}$, pumps and syringes (CMA Microdialysis, Sweden) were used in this study.

\section{In vitro characterization of microdialysis probes}

The in vitro probe recovery of Puerarin was determined by two methods: extraction efficiency method and retrodialysis method. All methods were carried out in a stirred vial with different stirring speed, solution or perfusate at $37 \pm 0.2^{\circ} \mathrm{C}$. Each experiment was described as follows.

\section{Retro-dialysis method}

In the retro-dialysis experiment, a probe was placed in a vial with $10 \mathrm{ml}$ saline in it. The standard solution of puerarin in saline was pumped through the probe at $1.5 \mu \mathrm{l} / \mathrm{min}$ for $2 \mathrm{~h}$. Thereafter, 6 samples were collected every 20 min. The concentration of puerarin in the samples and perfusate were determined by HPLC method as previously described. Delivery $\left(E_{D}\right)$, determined by retro-dialysis method, was computed as in Eq 1

$$
E_{\mathrm{D}}=\frac{C_{\text {in }}-C_{\text {out }}}{C_{\text {in }}} \times 100 \%
$$

\section{Extraction efficiency method}

In the extraction efficiency experiment, a probe was placed in a vial with $10 \mathrm{ml}$ standard solution of Puerarin while different drug-free solution was pumped through the probe at $1.5 \mu \mathrm{l} / \mathrm{min}$ for $2 \mathrm{~h}$. Thereafter, a total of 6 dialysate samples were collected every $20 \mathrm{~min}$. The concentration of puerarin in the collected samples and vial were determined by HPLC. Recovery $\left(E_{R}\right)$ was determined as in Eq 2.

$$
E_{R}=\frac{C_{\text {out }}}{C_{\text {solution }}} \times 100 \%
$$

\section{Data analysis}

Several samples were excluded because some of the inserts in the sample vials might have been be contaminated as they appeared pale when injected. 
Analysis of the data was performed by SAS 8.2 software using Student's $t$-test or ANOVA tests. Differences were considered significant at $p<$ 0.05 .

\section{RESULTS}

\section{Delivery and recovery}

In these experiments, the concentration of puerarin was set at $1 \mu \mathrm{g} / \mathrm{ml}$. Stirring speed was maintained at $100 \mathrm{rpm}$ in this experiment. $E_{R}$ and $E_{D}$ were 71.60 and $58.67 \%$, respectively.

There was significant difference $(p<0.01)$ between $E_{D}$ and $E_{R}$ for puerarin, which indicates that under certain conditions, substituting retrodialysis method for extraction efficiency method was not feasible. So, several factors affecting $E_{D}$ and $E_{R}$ were studied, in the following experiments.

\section{Influence of drug concentration on $E_{D}$ and $E_{R}$}

In Whitaker \& Lunte's experiments [7], $E_{D}$ of the target compound, doxorubicin, was significantly higher than $E_{R}$, which was ascribed to its strong absorption to membrane. The probe membrane became and remained red in color after perfusion also proved its absorption visually. However, puerarin is a colorless solution, and so solutions with different drug concentration were tested. Theoretically, $E_{D}$ or $E_{R}$ at different concentrations displayed no differences, if the drug has no adsorption properties [8]. The data are shown in Table 1.

Table 1: Influence of drug concentration to $E_{R}$ and $E_{D}$ (mean $\pm S D, n=5$ or 6 )

\begin{tabular}{lclc}
\hline \multicolumn{2}{c}{$\mathrm{E}_{\mathrm{D}}{ }^{\mathrm{a}}$} & \multicolumn{2}{c}{$\mathrm{E}_{\mathrm{R}}$} \\
\hline $\begin{array}{l}\text { Concentra- Average } \mathrm{E}_{\mathrm{D}} \\
\text { tion of } \\
\text { perfusate } \\
(\boldsymbol{\mu g} / \mathrm{ml})\end{array}$ & $\begin{array}{l}\text { Concentra- } \\
\text { Average } E_{R} \\
\text { tion } \\
\text { of drug- } \\
\text { containing } \\
\text { solution } \\
(\boldsymbol{\mu g} / \mathrm{ml})\end{array}$ \\
\hline 1.07 & $58.67 \pm 3.41$ & 1.06 & $71.60 \pm 1.79 *$ \\
2.08 & $61.27 \pm 0.84$ & 2.06 & $73.31 \pm 1.20 *$ \\
4.02 & $58.77 \pm 3.53$ & 3.99 & $71.77 \pm 1.46$ \\
\hline
\end{tabular}

${ }^{*} \mathrm{E}_{\mathrm{R}}$ is significantly different from $\mathrm{E}_{\mathrm{D}}$ at $p<0.01$, when the concentration is $1 \mu \mathrm{g} / \mathrm{ml}$; ${ }^{* *} E_{R}$ is significantly different from $\mathrm{E}_{\mathrm{D}}$ at $p<0.01$, when the concentration is $2 \mu \mathrm{g} / \mathrm{ml} ;{ }^{* * *} \mathrm{E}_{\mathrm{R}}$ is significantly different from $\mathrm{E}_{\mathrm{D}}$ at $p<0.01$, when the concentration is $4 \mu \mathrm{g} / \mathrm{ml}$

There were significant differences between $E_{R}$ and $E_{D}$ at each concentration, however, for the same method, the result of different concentrations did not shown significant differences.

\section{Probe clearance of puerarin}

The concentration of puerarin in the samples decreased sharply and was not detectable by the time second sample was taken, as shown in Fig 1.

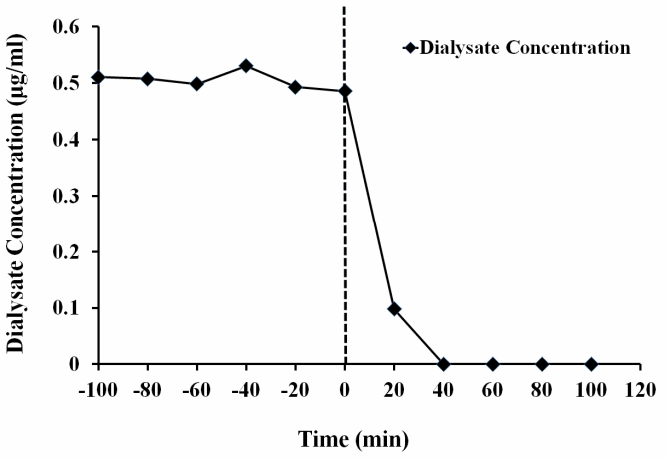

Fig 1: Probe clearance of puerarin

\section{Influence of stirring speed of probe on $E_{R}$ and $E_{D}$}

The delivery and recovery data at each speed are depicted in Fig 2. With increase in stirring speed, $E_{R}$ or $E_{D}$ rose gradually. The difference between delivery and recovery was directly related to stirring speed from 2.99 to $10.46 \%$.

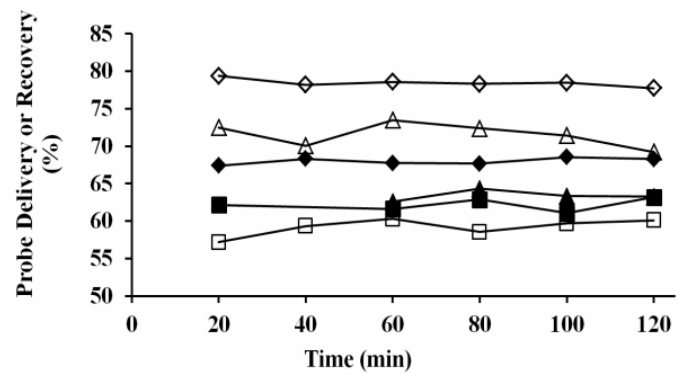

Fig 2: Delivery and recovery at various stirring speed. Key: $\square=$ delivery of $0 \mathrm{rpm}$ group; $\square=$ recovery of 0 rpm group; $\boldsymbol{\Delta}=$ delivery of $100 \mathrm{rpm}$ group; $\Delta=$ revovery of $100 \mathrm{rpm}$ group; $\diamond=$ delivery of $800 \mathrm{rpm}$ group; $\diamond=$ recovery of 800 rpm group. Note: Probe recovery is significantly different from delivery at $p<$ 0.01 at stirring speed of 0,100 and $800 \mathrm{rpm}$

\section{Influence of different solutions on $E_{R}$ and $E_{D}$}

The solubility of puerarin in the first two solutions (saline and saline containing $10 \%$ each ofethanol and propylene; 80/10/10, v/v/v)) was 3.36 and $12.01 \mathrm{mg} / \mathrm{ml}$, respectively. Solubility in the third solution (saline containing $5 \% \mathrm{HP}-\beta$ CD; $5 / 100, w / v)$ ) was $>13.09 \mathrm{mg} / \mathrm{ml}$, probably because more drug molecules might be trapped by HP- $\beta-C D$ after treatment by ultrasonic waves. 
Due to the trapping property of HP- $\beta-C D$, retrodialysis method was not used for it. Most of the drug may be trapped after agitation when the perfusion solution is prepared and this may affect its detection directly. In order to minimize the risk of trapping by HP- $\beta-C D$, the stirring speed in these experiments was set at $0 \mathrm{rpm}$. The results are depicted in Fig 3 . $E_{D}$ decreased in solution 2 while $E_{R}$ increased slightly in solutions 2 and 3 , when compared with saline group.

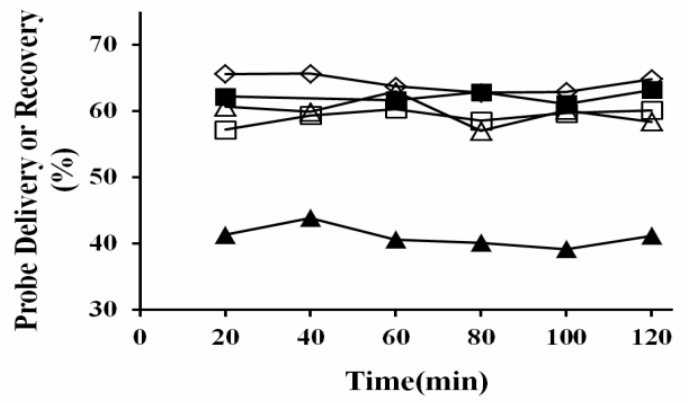

Fig 3: Delivery and recovery of puerarin in different solutions. Key: $\mathbf{a}=$ delivery of solution 1 ; $\square=$ recovery of solution $1 ; \boldsymbol{\Delta}=$ delivery of solution $2 \quad \Delta=$ recovery of solution $2 ; \diamond=$ recovery of solution 3 . Note: Delivery of solution 2 is significantly different from delivery of solution 1 at $p<0.01$ while recovery of solution 3 is significantly different from recovery of solution 1 at $p<0.01$.

\section{DISCUSSION}

In microdialysis experiments, both recovery and delivery should be tested at steady state. Due to the fact that they are vulnerable to numerous factors, great differences are observed [9].

\section{Influence of length of membrane on $E_{R}$ and $E_{D}$}

Both of $E_{D}$ and $E_{R}$ decreased significantly, as in Fig 4 but the difference should not be ignored.

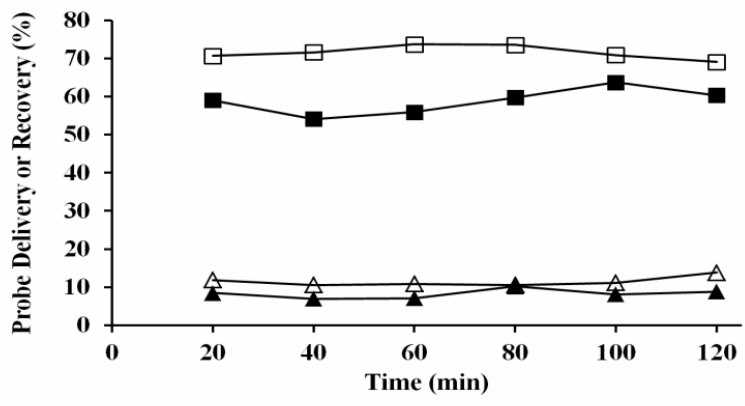

Fig 4: Delivery and recovey of puerarin with different length of probe membrane. Key: $=$ delivery of $10 \mathrm{~mm}$ membrane; $\square=$ recovery of $10 \mathrm{~mm}$ membrane; $\boldsymbol{\Delta}=$ delivery of $2 \mathrm{~mm}$ membrane; $\triangle$ = recovery of $2 \mathrm{~mm}$ membrane
Whitaker and Lunte [7] found that the absorption of the membrane led to the difference between $E_{D}$ and $E_{R}$. It was not feasible to replace $E_{R}$ with $E_{D}$ when adsorption existed. However, the results of our absorption experiments showed that the difference was irrelevant to adsorption. The membrane did not adsorb puerarin.

The viscosity of blood and depth of anesthesia may affect the flow velocity of blood of animals in vivo experiments. A fast rate may be helpful to the diffusion of analyte. So we chose stirring speed in vitro to simulate the flow velocity of blood in vivo experiments. In the present study, the stirring speed exerted a tremendous influence on the results. $E_{R}$ or $E_{D}$ rose gradually with increase in stirring speed from 0 to $800 \mathrm{rpm}$, which agree with the results of Stenken's experiments [10]. For the retro-dialysis experiment, stirring can avoid high local concentration, which is helpful to the diffusion of analyte. For the extraction efficiency method, the fluid boundary layer [11], which affects mass transport through the membrane, may be reduced by high stirring speed. Besides, a low stirring speed may minimize the gap between $E_{R}$ and $E_{D}$. The results indicate that, for some compounds, delivery cannot be regarded as recovery in in vivo experiment, especially when the animals are awake.

Frequently, different additives are added to the perfusate in order to increase in vivo recovery of targeting compounds. We investigated three different solutions. In all of these solutions, there were significant differences between $E_{R}$ and $E_{D}$. It is noteworthy that, compared with the saline group, $E_{D}$ of solution 2 reduced, while $E_{R}$ increased slightly. This also indicates that additives in perfusate can increase trecovery, but will also enlarge the gap between $E_{R}$ and $E_{D}$. When additives are added to the perfusate solution, delivery cannot be considered to be equivalent to recovery of the probe in in vivo experiments when calculating the real concentration of ECF.

Shortening of length of probe membrane may also lead to decrease in $E_{R}$ and $E_{D}$. Here too recovery was significantly different from delivery.

In in vivo microdialysis experiments, the real concentration of analyte in ECF can be calculated by dividing the sample concentration by recovery. However, this recovery is obtained by in vivo retro-dialysis experiment. The method is based on the fact that, under certain conditions, $E_{R}$ is equal to $E_{D}$. In the present case, the difference between $E_{R}$ and $E_{D}$ cannot 
be eliminated. Hence, the actual concentration of analyte in vivo cannot be calculated as described above. It is necessary to introduce another coefficient, $k$, as suggested by other workers $[12,13]$. $C_{E C F}$ can be calculated according to Eqs 3 and 4 . Alternatively, in vivo recovery can be obtained by no-net-flux method [14].

$$
\begin{aligned}
& k=\frac{E_{R(\text { inviro })}}{E_{D(\text { inviro })}}=\frac{E_{R(\text { invivo })}}{E_{D(\text { invivo })}} \\
& C_{E C F}=\frac{C_{\text {sample }}}{k \llbracket E_{D(\text { invivo })}} \ldots \ldots \ldots . . . . . .
\end{aligned}
$$

\section{CONCLUSION}

These results indicate that, $E_{D}$ should not be considered a substitute for $E_{R}$, especially when one needs to know the real concentration of analyte in ECF.

\section{ACKNOWLEDGEMENT}

This work was supported in part by the National Natural Science Foundation of China (nos. 81102816 and 81073057) and Innovation Team Development Program of Beijing University of Chinese Medicine (nos.2011-CXTD-13 and JYBZZ-JS021).

\section{REFERENCES}

1. Moset/ha K, Torto N. Determination of $\mathrm{Cu}$ and $\mathrm{Ni}$ in plants by microdialysis sampling: Comparison of dialyzable metal fractions with total metal content. Talanta. 2007; 71: 766-770.

2. Latzke D, Marhofer, Kettner SC. Pharmacokinetics of the local anesthetic ropivacaine after transversus abdominis plane block in healthy volunteers. Eur J Clin Pharmacol. 2012; 68: 419-425.
3. Westerhout J, Ploeger B, Smeets J. Physiologically-based Pharmacokinetic Modeling to Investigate Regional Brain Distribution Kinetics in Rats. AAPS J. 2012; 14: 543-553.

4. Su D, Song YG, Geng LL. Ocular Pharmacokinetic Study of L-Carnosine and N-Acetyl-L-carnosine in Rabbit by Microdialysis Coupled with UPLC-MS-MS. Chromatographia. 2011; 73: 1189-1195.

5. Kaur IP, Aggarwal D, Singh H. Improved ocular absorption kinetics of timolol maleate loaded into a bioadhesive niosomal delivery system. Graefes Arch Clin Exp Ophthalmol. 2010; 248: 1467-1472.

6. Chaurasia CS. In vivo microdialysis sampling: theory and applications. Biomed Chromatogr. 1999; 13: 317332.

7. Whitaker G, Lunte CE. Investigation of microdialysis sampling calibration approaches for lipophilic analytes: Doxorubicin. J Pharm Biomed Anal. 2010; 53: 490-496.

8. Schuck VJA, Rinas I, Derendorf H. In vitro microdialysis sampling of docetaxel. J Pharm Biomed Anal. 2004; 36: 807-813.

9. Bungay PM, Morrison PF, Dedrick RL. Steady-state theory for quantitative microdialysis of solutes and water in vivo and in vitro. Life Sci. 1990; 46: 105-119.10 Stenken JA, Topp EM, Southard MZ. Examination of Microdialysis Sampling in a Well- Characterized Hydrodynamic System. Anal Chem. 1993; 65: 2324-2328.

11. Stenken JA. Methods and issues in microdialysis calibration. Anal Chim Acta. 1999; 379: 337-358.

12. Qiao JP, Chu FM, Hou PL. Microdialysis combined with liquid chromatography-tandem mass spectrometry for the determination of 6-aminobutylphthalide and its main metabolite in the brains of awake freelymoving rats. J Chromatogr B Analyt Technol Biomed Life Sci. 2004; 805: 93-99.

13. Gao CY, Li XR, Li YH, Wang LJ, Xue M. Pharmacokinetic interation between puerarin and edaravone, and effect of borneol on the brain distribution kinetics of puerarin in rats. J Pharm Pharmacol. 2010; 62: 360-367.

14. Käenmäki1 M, Tammimäki1 $A$, Myöhänen $T$. Quantitative role of COMT in dopamine clearance in the prefrontal cortex of freely moving mice. $J$ Neurochem. 2010; 114: 1745-1755. 